\title{
Development of medical imaging technologies is the best way to advance clinical diagnostic accuracy and there is no such thing as VOMIT
}

\author{
${ }^{1} \mathrm{P}$ McCoubrie, ${ }^{2} \mathrm{JH}$ Reid \\ ${ }^{1}$ Consultant Radiologist, Department of Radiology, Southmead Hospital, Bristol; ${ }^{2}$ Consultant Radiologist, Department of Radiology, Borders \\ General Hospital, Melrose
}

\begin{abstract}
We recently published a commentary on the impact of blood biomarkers in clinical decision-making. In this issue we shift to a similar contemporary debate surrounding over-reliance on imaging technologies to make diagnoses, often without a clinical rationale other than to rule out pathology. This strategy is not without harm to patients as illustrated by both of our experienced contributors. The place and responsibility for missed or irrelevant diagnoses following imaging will often rest on little more than inept clinical targeting, although as McCoubrie points out, the skilled radiologist may have some role in tempering everything from overzealous interpretation to simple error. Given that many techniques are based on (albeit falling) X-ray exposure and involve vastly expensive (and routinely redundant) technologies operating almost continuously, the role of skilled radiological input is more essential than ever for reducing VOMIT. Can we control inadequate imaging request strategies?
\end{abstract}

\author{
Correspondence to $\mathbf{P}$ McCoubrie, \\ Department of Radiology, \\ Southmead Hospital, \\ Bristol BSIO 5NB, UK
}

tel. +44 (0)775 $369 \quad 1736$

e-mail paul.mccoubrie@nbt.nhs.uk

Correspondence to JH Reid,

Department of Radiology,

Borders General Hospital

Melrose TD6 9BS, UK

e-mail

John.reid@borders.scot.nhs.uk

KEYWORDS Clinical decision-making, medical imaging, 'rule-out' testing, incidentalomas, radiation dose, demise of bedside medicine

DECLARATION OF INTERESTS No conflicts of interest declared.

\section{VOMIT is overstated, preventable and flawed}

\author{
P McCoubrie
}

Victim of medical imaging technologies (VOMIT) is an overstated, preventable and flawed concept. Not all incidental findings are trivial. Anxiety-inducing false positive results aren't intrinsic to modern scanning but can be prevented by good radiological practice. Furthermore, defensive medical practice is a preventable cause of the modern rise in benign incidental findings.

Richard Hayward, a paediatric neurosurgeon, first described VOMIT in a BMJ personal view in 2003.' He presented two hypothetical examples of 'innocent pathology' found on magnetic resonance imaging (MRI), which induced considerable worry and anxiety in the patient and their families. This anxiety was fuelled by internet-based research and needed considerable time on behalf of the specialist to allay fears.

This 'acronym for our time' seemed to strike a chord; a flurry of letters were sent to the editor. Further facetious acronyms have been suggested including brainless application of radiological findings (BARF) and ominous referrals for dubious unattested radiographic examinations (ORDURE), leading to suggestions for the setting up of the campaign for real ailments (CAMRA).

The phrase VOMIT has subsequently passed into common medical parlance. Its use now encompasses all patients who suffer physically as well as mentally as a result of false positive scan findings. In particular, it also includes those who undergo unnecessary further interventions for what turns out to be benign pathology.

The latter group have been described as suffering from 'Ulysses syndrome'. First described by Rang in 1972,2 patients with Ulysses syndrome 'make a long journey through the investigative arts and experience a number of adventures before reaching their point of departure once again,' akin to Ulysses' 20 years of dramatic exploits on trying to return home after the Trojan war.

It is increasingly recognised that it isn't just radiological imaging modalities: it applies to all investigations that are highly sensitive but not particularly specific. The prostatespecific antigen (PSA) test for prostate cancer is another 
case in point, jokingly referred to as the 'promoting stress and anxiety test'.

Victim of medical imaging technology isn't a particularly new idea; the term 'incidentaloma' was coined 30 years ago. ${ }^{3}$ Since this original description of increasingly found incidental adrenal lesions, it has emerged that if one looks closely enough, most organs commonly contain benign masses that are often difficult to distinguish from early malignancies. The principles underlying VOMIT are now considered beyond question. The increasing accuracy brought by advances in imaging technology brings an inevitable flurry of incidental findings. It is a hegemonic assumption that 'red herrings' are an inevitable part of modern medicine. It logically follows that the more modern the imaging technology, the more VOMIT it will produce. Increased availability of modern scanners will merely result in more VOMIT. The ultimate extrapolation of this argument is that expansion of radiological imaging services will not produce population health gains; expansion should be therefore resisted. There are many reasons why this is wrong. In truth, VOMIT is a flawed principle.

Why is it flawed? First, incidental isn't always trivial. Second, VOMIT is overstated but not intrinsic to scanning, just usually down to poorly performing radiologists. Third, I will contend the rise in incidental findings is due to defensive medicine driving increasing scanning rates.

\section{INCIDENTAL ISN'T ALWAYS TRIVIAL}

It is often forgotten that some 'incidental' findings are not innocuous. For example:

- Unexpected malignancies are commonly identified. In a large series of nearly I I,000 patients undergoing bowel cancer screening with computed tomography (CT) colonography (Figure I), ${ }^{4}$ unexpected extracolonic malignancies were discovered in $0.6 \%$ of patients. Interestingly, this is over double the rate of colonic malignancies in their series.

- Serendipitous significant findings are worthwhile. Over $50 \%$ of renal tumours are now found incidentally. ${ }^{5}$ Moreover, survival from such asymptomatic tumours is more favourable than can be explained by differences in stage, grade or patient demographics.

- Medical advances change the way we view 'incidental findings'. Coronary artery calcification used to be thought an incidental finding on CT. However it turns out to be a direct indicator of atheroma and hence its severity is an extremely strong predictor of cardiovascular risk. ${ }^{6}$ Coronary calcium 'scoring' is now a common indication for CT.

\section{POORLY PERFORMING RADIOLOGISTS}

A good radiologist should be able to sort the wheat from the chaff and thereby prevent VOMIT at source. Truly benign incidental findings are either totally ignored or positively identified and then firmly dismissed; significant incidental findings are highlighted appropriately. A good radiologist equivocates only when essential. Borderline findings are specified, the reason for equivocating should be highlighted and then a plan for solving the dilemma is suggested.

There are three prerequisites to minimisation of equivocation:

I. The radiologist should be an expert in the body part being scanned; they should be up-to-date and appropriately knowledgeable about the pitfalls of scanning particular organs. Sub-specialisation in radiology is a necessary development given the ever-increasing knowledge base. ${ }^{7}$ For example, there are widely accepted guidelines for safe management of incidental lung nodules that clearly outline the most appropriate follow-up strategy. ${ }^{8}$

2. The second is that images should be of the best possible quality and the radiologist should fully assess them. To make the best assessment, scans should be specifically protocolled to answer the clinical question (e.g. use of IV contrast). Although all radiologists are time pressured they should take time to assess the images fully and thereby reduce error. Such proven techniques including altering the window settings, changing slice width, multiplanar reformatting and appropriate use of $3 \mathrm{D}$ imaging. ${ }^{9}$

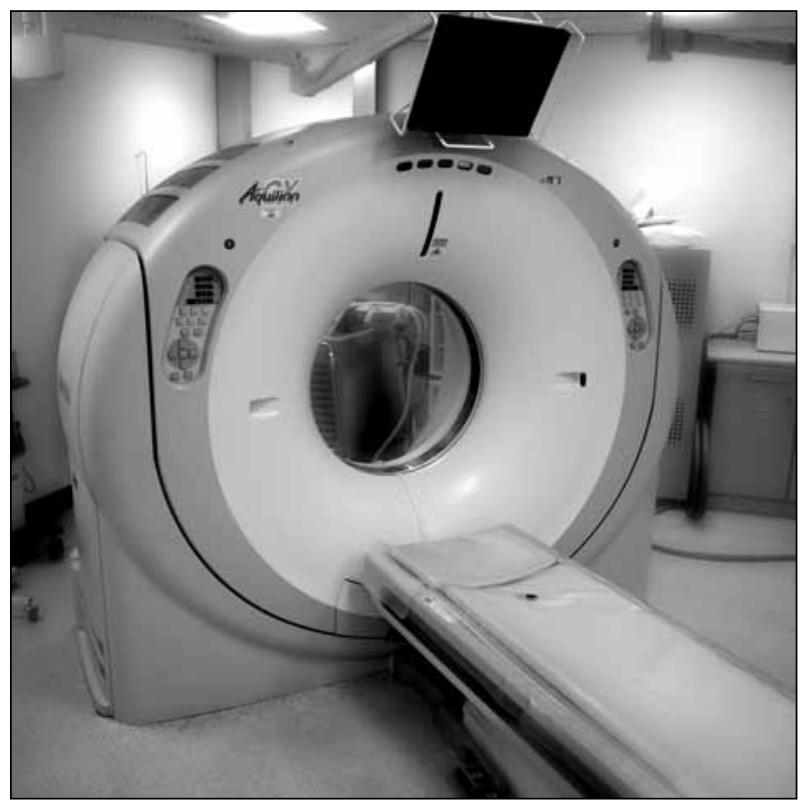

FIGURE I The latest generation of computed tomography (CT) scanners are highly accurate but demand careful use. 
3. Lastly, their findings should be clearly reported. The written radiology report is the key method of communication. There is evidence that many reports are unclear despite published guidance on best practice. ${ }^{10} \mathrm{~A}$ good radiology report should answer the clinical question in as brief,clear and unambiguous a fashion as possible. Where there is equivocation, there should be pertinent advice regarding further management and follow-up.

Too often radiologists 'hedge'; they use evasive statements to avoid the risk of commitment. Such vague and ambiguous reports are positively dangerous. A review of medico-legal cases by Berlin" highlighted that vagueness in reporting can easily lead to delayed diagnosis. Victim of medical imaging is most often caused by 'hedging' over benign findings; failure to categorise findings adequately.

\section{THE RISE OF DEFENSIVE MEDICINE}

A common phenomenon that is creeping insidiously into clinical practice is the 'rule-out' scan. Wanting to 'exclude' diseases heralds a move away from traditional medical diagnostic acumen, based on knowledge and expertise. The heart of Western medical thinking, probabilistic hypothetico-deductive reasoning, is rejected. Diagnostic indecision is embraced 'just in case'. It is clinically and morally lazy.

It is also highly wasteful of taxpayer's money. Inadequate triage leads to high negative rates and cost inefficiency. For example, $\sim 25 \%$ of CT pulmonary angiograms were positive a decade ago; it appeared to be a worthy thing to do. Now our local pick-up rate is half that but some institutions report single figures.

Moreover, this negative investigational paradigm should be distinguished from the meritorious desire to investigate a patient fully. 'Ruling-out' betrays the doctorpatient relationship from within. Inappropriately extensive investigation apes thorough, and hence caring, medicine. ${ }^{12}$ The truth is that the doctor is transferring risk to the patient under the guise of being thorough. 'Ruling-out' is defensive medicine, plain and simple.

The reason that rule-outs produce more VOMIT is simple. A total of $5 \%$ of healthy people are statistically abnormal. If a person has 20 tests, there is a $66 \%$ chance of one or more abnormal results. Also, the clinical history will bias interpretation. To explain symptoms, the radiologist is forced to postulate that benign-looking findings could conceivably be symptomatic. Add unfocused tests to an unclear clinical picture and the waters muddy still further.

Professor Sir Howard Middlemiss, who died nearly 30 years ago, was a radiological giant of his time whose memory lives on. It was said that he wanted a sign put up in the reception area of the radiology department of the Bristol Royal Infirmary that said, 'We are not in the business of exclusion'. This adage could equally be a rallying cry for twenty-first century radiologists.

\section{CONCLUSION}

Victim of modern medical imaging is avoidable. A significant number of incidental findings are not trivial. A good radiologist should clearly categorise the vast majority of incidental findings, minimising uncertainty over future management. If the negative 'rule-out' investigational paradigm is shunned, the chance of false positive tests is reduced. It is also overstated. As Rang noted some forty years ago:

[It] runs a short course and no mortality or permanent harmful effects have yet been noted. [lt] is more benign than the false-negative syndrome and certainly carries a better prognosis than uninvestigated disease. ${ }^{2}$

\section{REFERENCES}

I Hayward R. VOMIT (victims of modern imaging technology): an acronym for our times. BMJ 2003; 326:1273-3. http://dx.doi. org/l0.1 I36/bmj.326.740I.1273

2 Rang M.The Ulysses syndrome. Can Med Assoc J 1972; 106:122-3.

3 Geelhoed GW, Druy EM. Management of the adrenal 'incidentaloma'. Surgery 1982; 92:866-74.

4 Pickhardt PJ, Kim DH, Meiners RJ et al. Colorectal and extracolonic cancers detected at screening CT colonography in 10,286 asymptomatic adults. Radiology 2010; 255:83-8. http://dx.doi. org/l 0.1 I48/radiol.09090939

5 Palsdottir HB, Hardarson S, Petursdottir $V$ et al. Incidental detection of renal cell carcinoma is an independent prognostic marker: results of a long-term, whole population study. J Urol 2012; 187:48-53. http://dx.doi.org/I0.1016/j.juro.20II.09.025

6 Budoff MJ,Achenbach S, Blumenthal RS et al.Assessment of coronary artery disease by cardiac computed tomography:a scientific statement from the American Heart Association Committee on Cardiovascular Imaging and Intervention, Council on Cardiovascular Radiology and Intervention, and Committee on Cardiac Imaging, Council on Clinical Cardiology. Circulation 2006; II4:I76I-9I. http://dx.doi.org//0.I I6I/ CIRCULATIONAHA.106.178458

7 FitzGerald R. Radiological error: analysis, standard setting, targeted instruction and teamworking. Eur Radiol 2005; 15:1760-7. http:// dx.doi.org/10.1007/s00330-005-2662-8

8 MacMahon $\mathrm{H}$, Austin JH, Gamsu G et al. Guidelines for management of small pulmonary nodules detected on CT scans: a statement from the Fleischner Society. Radiology 2005; 237:395-400. http:// dx.doi.org/I0.I I48/radiol.237204/887

9 Horton KM, Johnson PT, Fishman EK. MDCT of the abdomen: common misdiagnoses at a busy academic center. AJR Am J Roentgenol 2010; 194:660-7.http://dx.doi.org/ 10.22 I4/AJR.09.3280

10 Wallis A, McCoubrie P. The radiology report: are we getting the message across? Clin Radiol 2011; 66:1015-22. http://dx.doi. org/10.1016/j.crad.2011.05.013

II Berlin L. Pitfalls of the vague radiology report. AJR Am J Roentgenol 2000; 174: I5II-8.

12 MacFadyen RJ. Referral for diagnosis: effectiveness not activity or expediency is a priority. $J R$ Coll Physicians Edinb 2012; 42:5-7. http://dx.doi.org//0.4997/JRCPE.2012.102 


\title{
Expanding availability and access to medical imaging without the intelligent engagement of referring clinicians is not the best way to improve diagnostic accuracy
}

\author{
JH Reid
}

Expanding availability and access to medical imaging without the intelligent engagement of referring clinicians is not the best way to improve diagnostic accuracy. It leads to clinical laziness, 'supermarket requesting' and progressive de-skilling which at best will ensure that future generations of physicians will operate at a clinically challenged level and at worst bring about the ultimate demise of clinical competency. It will also ensure that in a cash-strapped future, deserving patients will have to compete with diagnostic dross and will not reap the full benefit of the powerful diagnostic technologies available to us. It also adds to an overburdened radiological community which is already one of the poorest resourced in Europe in terms of manpower and equipment. There are indeed victims of overzealous imaging. The greater the number of unnecessary tests, the greater the number of false positives and incidentalomas. For the future good of clinical medicine, there should be a zero-tolerance approach to poor quality requests and the gratuitous use of diagnostic imaging.

\section{VICTIMS OF OUR OWN SUCCESS?}

It is a sad reflection on how short our memories are that we need to be reminded on a frequent basis that the good old days were in fact the bad old days: when patients died regularly with the wrong diagnosis and when exploratory laporotomy or autopsy were often the only methods of reaching anything like a clinical conclusion.' Post-mortems have declined to record lows in Scotland not just because of public distaste but because they are superfluous in many cases. Pre-mortem testing has refined and clinched diagnoses even if the advances in treatment have not kept up. For those too young to have lived through the golden age of the great breakthroughs in cross sectional imaging, it is impossible now to imagine approaching an acute brain, thorax or abdomen without a computed tomography (CT) scan. So does the ascendency of radiology mean that physicians and surgeons should fear being reduced to clinical automatons whose bedside skills may atrophy never to return and does it automatically follow that there will be a rise in victims of modern imaging technology (VOMIT)? ${ }^{2}$

\section{VOMIT}

Despite the vast majority who benefit from radiology there are unquestionably patients who suffer unnecessary anxiety and further unpleasant or even dangerous tests because of the failure to comprehend the nature of modern imaging, including its limitations. This is even more ironic in the case of patients who self-refer for whole body CT scans as a form of health check. It has been reported that up to $37 \%$ of these patients may end up having further tests or imaging to resolve incidental findings. ${ }^{3}$ These figures of course have to be approached with a certain degree of caution since this type of testing is often done within an environment of substantial cash incentives.

With specific regard to the VOMIT concept however I think as an 'arch conspiracy theorist' that the term was coined with a dual purpose in mind. The initial intention was to highlight to the medical world the rising number of false-positives and incidentalomas that seem to plague the apparently previously untroubled life of physicians and surgeons. Subconsciously however, I think it was to shift some of the guilt from an increasingly dependent clinical body to their radiological colleagues for the occasional mess they were finding themselves in. It's a bit like heroin addicts trying to blame poppy growers in Afghanistan for their habit. Increased efficacy and easy availability of any commodity usually leads to higher demand but it should not necessarily lead to sloppier thinking. And let's not be shy about it: in the resourcelimited UK the demand is emanating from clinicians themselves, and occasionally driven by poorly thought through guidelines.

All is not lost: clinicians and radiologists can collude to seriously reduce or even abolish VOMIT by employing clinical nous to focus requests, by resisting the temptation to hit with a sledgehammer everything that looks remotely like a nail and to avoid bypassing the tried and tested clinico-pathological method in favour of spinal reflex defensive 'what-if?' medicine. Radiologists should also sufficiently acquaint themselves by adequate experience and apprenticeship with the range and benignity of most incidental findings and learn to couch their reports in an unequivocal fashion that transmits confidence to the clinician. ${ }^{4}$

\section{UNDERSTANDING INCIDENTALOMAS}

There is absolutely no doubt that the stunning resolution of modern scanners and the sharp eyes of radiologists has revealed a whole new menagerie of incidental anatomical curiosities. This is not a surprise and is a direct function of the quality of the imaging. For good 
reason we are now able to visualise many diseases at an embryonic stage (e.g. early lung cancer) never before imagined. Unfortunately for the radiologist however, nascent pathology has many guises before it gets to the point that the foundation year one doctor can see.

Gone are the halcyon days when one could say with complete truthfulness that 'no liver metastases are visible at this time' when looking at fuzzy I2-slice CT of the upper abdomen. Today, overlooking a barely perceptible low attenuation lesion in a 500 slice 'routine' follow-up scan of someone with a prior history of colonic carcinoma could (and does) propel the radiologist towards a lawsuit.

The challenge for the radiologist is therefore to differentiate the signs of early disease from purely incidental findings of little clinical import: in a recent study of patients undergoing cardiac CT, $42 \%$ of patients scanned had incidental findings of which only I\% was significant (ranging from confirmed malignancy to vascular thrombus, aortic dissection and ruptured breast implants). The commonest incidental findings were lung nodules, none of which became significant during the 18-month follow up period. There was a significant cost associated with additional tests (around US\$I,000 per patient) and one patient suffered a major complication related to the investigation of an incidental finding. ${ }^{5}$

To reiterate: the radiologist and the referring clinician should be sufficiently experienced to recognise these incidental observations for what they are and firmly reject them from the immediate clinical scenario.

\section{CLINICAL DESKILLING}

As a radiologist, it may seem strange to emphasise the need for clinical upskilling which on the face of it could diminish my own sense of worth or the need for my specialty to become even more central to modern medicine than it already is. On the contrary, the clinicians I enjoy working with most call on radiology like a precision instrument to confirm specific clinical theses or to strategically resolve an impenetrable conundrum. Those I enjoy working with least use my service like a cudgel, as they randomly bludgeon a diagnosis to death. The rejection of flabby thinking and a return to the original primacy of proper clinical history and examination should be inculcated from early medical school. Failure to do this will result in hyposkillia which if not corrected will lead to the terminal decline in clinical skills. ${ }^{6}$

Writing in the Texas Heart Institute Journal, ${ }^{7}$ Herbert Fred mourned the passing of clinical skills:
For nearly four decades now, I have watched with sorrow the progressive demise of bedside medicine. Admittedly, the advent of ultrasonography, echocardiography, computed tomography (CT), and magnetic resonance imaging has enabled us to establish diagnoses with speed, accuracy, and safety never before imagined. At the same time, however, overreliance on these technologic marvels has crippled physicians' use of the mind and the five sensory faculties to make diagnoses. Jumping from the patient's chief complaint to a host of tests and procedures has become virtually routine. And when that approach fails, the physician typically orders more tests and seeks numerous consultations.

Professor Fred, I think, says it all.

\section{RADIATION EXPOSURE}

There is no doubt that too much radiation is bad for you and that the radiation received from diagnostic imaging has risen dramatically in the last ten to fifteen years. It is estimated that radiological procedures contribute to over $50 \%$ of the annual radiation exposure of American citizens now, compared to only $15 \%$ in $1980 .{ }^{8}$ Computed tomography is now implicated as one of the main sources of man-made radiation, with numbers of examinations in America rising from three million CT scans per year in 1980 to 80 million now.' Studies are suggesting there could be as many as 29,000 excess cancers per year in the USA due mainly to CT scanning. ${ }^{10}$

Alarming though these theoretical models are, the risk from diagnostic imaging versus the consequences of delayed or wrong diagnosis has probably been somewhat overemphasised for the sake of creating eye-catching stories in the media. The reality is that radiation doses for most radiological procedures have dropped dramatically in the last five years: for example a cardiac CT for non-invasively imaging the coronary arteries has reduced from $18 \mathrm{mSv}$ (the equivalent of nine years background radiation) to less than $2 \mathrm{mSv}$. These doses are likely to continue to fall for virtually all radiological procedures as manufacturers respond to increasing public awareness.

\section{RESOURCE LIMITATIONS}

Despite many innovations in radiology (yet to be routinely embraced by other clinical sectors) such as seven-day working, extended hours, skill-mix, outsourcing, telemedicine, electronic requesting, and voice recognition, radiological infrastructure in the UK is most assuredly not limitless. With respect to 


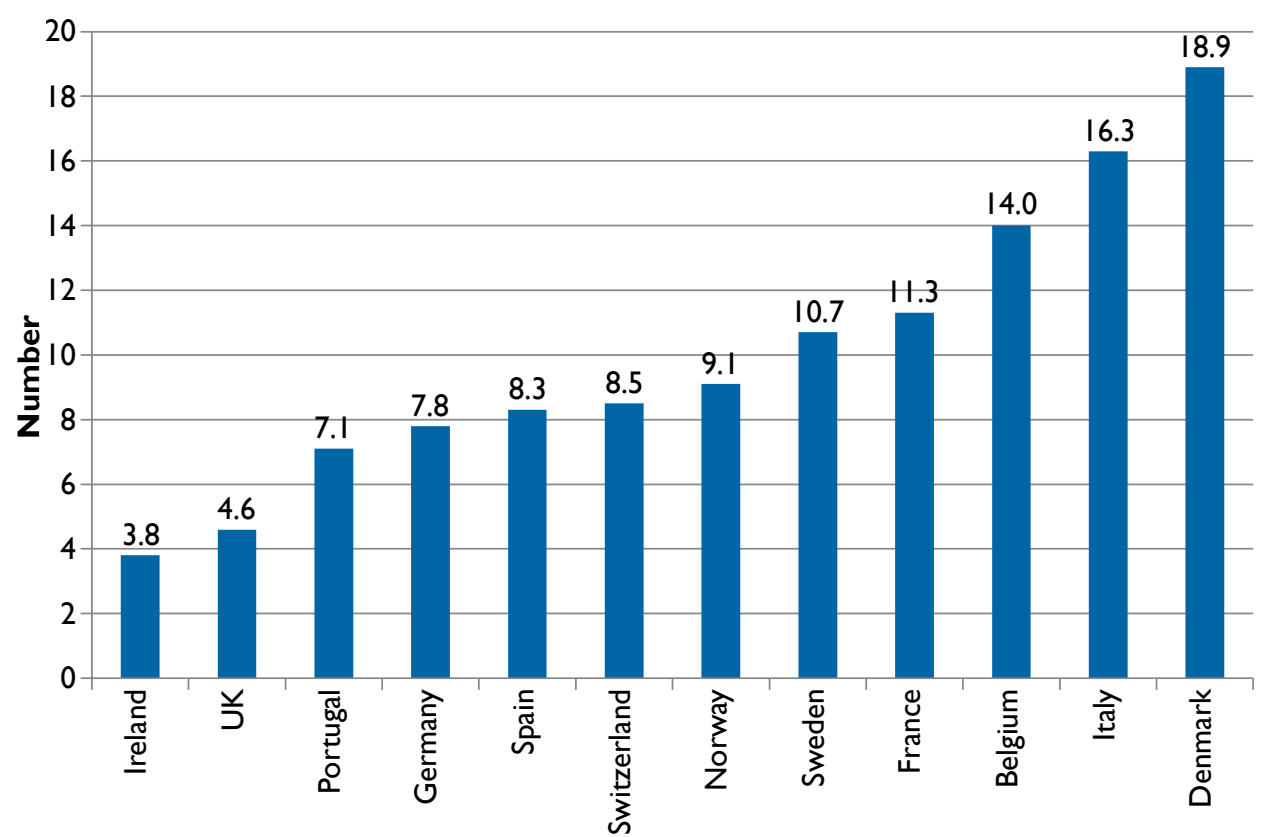

FIGURE I Number of clinical radiologists per 100,000 population. ${ }^{12}$

equipment base, the particularly hard pressed modality of CT is significantly below par. According to the Organisation for Economic Cooperation and Development (OECD) figures for 20II, the UK, despite being the nation who invented it, has the second lowest recorded data in the developed world (Hungary is poorest) at $8.9 \mathrm{CT}$ scanners per million inhabitants. This compares with 10.2 for Chile, I 3.8 for Slovakia, I6.4 for Southern Ireland, 29.4 for Denmark, 44.0 for Australia and a huge 97.3 for Japan." By 'sweating our assets off' in the UK the number of CT examinations has risen by $86 \%$ and magnetic resonance imaging (MRI) examinations by $125 \%$ since 2005 . But irrespective of how hard or how lean politicians think our scanners should be driven, we are firmly at the bottom of the resource heap.

Manpower is in equally short supply and a 2012 radiological workforce survey by the Royal College of Radiologists (RCR) finds us also close to the bottom on the manpower graph (Figure I). The same survey confirmed that $9 \%$ of consultant posts remained unfilled. ${ }^{12}$

The RCR document highlighted several pressure points:

The workload for the clinical radiologist has increased hugely, not only in volume but also complexity. This has been driven by the ever-expanding choice of available imaging techniques and the increasing inherent complexity of the examinations themselves. Regardless of population growth, it is widely accepted that the workload of clinical radiologists will continue to increase with further advances in imaging technology and the impact of commissioning.
Furthermore, a UK study showed clinical radiologists appear to be at greater risk of burnout than consultants working in other specialties predominantly related to workload and inadequacies in current staffing and facilities. ${ }^{13}$

So as one can see we are not exactly overflowing with spare capacity.

\section{CONCLUSION}

Clinicians today have at their disposal an imaging armoury that would have been the envy of their forebears. However, like any weapon, if poorly directed it can lead to grief for all concerned. If the future is approached in a collegiate fashion then patients, clinicians, radiologists and the public purse will benefit. If we communicate like an estranged family the only winners will be the lawyers. Intelligent use of modern imaging is the only way forward. 


\section{REFERENCES}

I Gambino SR. The autopsy. The ultimate audit. Arch Pathol Lab Med 1984; 108;444-5.

2 Hayward R. VOMIT (victims of modern imaging technology): an acronym for our times. BMJ 2003; 326:1273-3. http://dx.doi. org/I0.II36/bmj.326.740I.1273

3 Furtado CD, Aguirre DA, Sirlin CB et al. Whole-body CT screening: spectrum of findings and recommendations in 1192 patients. Radiology 2005; 237:385-94. http://dx.doi.org//0.II48/ radiol.237204I74I

4 Dunnick NR, Langlotz CP. The radiology report of the future: a summary of the 2007 Intersociety Conference. J Am Coll Radiol 2008; 5:626-9. http://dx.doi.org/10.1016/j.jacc.2009.06.026

5 Machaalany J, Yam Y, Ruddy TD et al. Potential clinical and economic consequences of noncardiac incidental findings on cardiac computed tomography. J Am Coll Cardiol 2009; 54: I533-4I.

6 Fred HL. Hyposkillia: deficiency of clinical skills. Tex Heart Inst J 2005; 32:255-7.

7 Fred HL. The downside of medical progress: the mourning of a medical dinosaur. Tex Heart Inst J 2009; 36: 4-7.

8 Mettler FA Jr, Bhargavan M, Faulkner $\mathrm{K}$ et al. Radiologic and nuclear medicine studies in the United States and worldwide: frequency, radiation dose, and comparison with other radiation sources: 1950-2007. Radiology 2009; 253:520-31. http://dx.doi org/l 0.I I 48/radiol.25320820I0
9 Brenner DJ, Hricak H. Radiation exposure from medical imaging: time to regulate? JAMA 20 10;304:208-9. http://dx.doi.org/l 0.100I/ jama.2010.973

10 Berrington de Gonzalez A, Maheshi M, Kim KP et al Projected cancer risks from computed tomographic scans performed in the United States in 2007. Arch Intern Med 2009; 169:207I-7. http:// dx.doi.org/ 10.100 I/archinternmed.2009.440

II Organisation for Economic Co-operation and Development (OECD) [Internet]. OECD figures for 20I I. Available from: http://stats.oecd.org/

12 Royal College of Radiologists. Investing in the clinical radiology workforce - the quality and efficiency case [Internet]. London: Royal College of Radiologists; 2012 [cited 2012 Oct 30]. Available from: http://www.rcr.ac.uk/docs/radiology/pdf/RCR_CRWorkforce_ June20I2.pdf

I3 Graham J, Ramirez AJ, Field S et al. Job stress and satisfaction among clinical radiologists. Clin Radiol 2000; 55:182-5. http:// dx.doi.org/I0.1053/crad. I999.0379 